\title{
Cost Effective Fabrication of a Triboelectric Energy Harvester Using Soft Lithography
}

\author{
Jun-Young Lee ${ }^{\mathrm{a}, \mathrm{b}}$, Tae-hoon Sung ${ }^{\mathrm{a}}$, and Jong-Souk $\mathrm{Yeo}^{\mathrm{a}, \mathrm{b}_{*}}$ \\ ${ }^{a}$ School of Integrated Technology, Yonsei University, Incheon 406-840 \\ ${ }^{b}$ Yonsei Institute of Convergence Technology, Yonsei University, Incheon 406-840 \\ (Received June 12, 2013, Revised July 3, 2013, Accepted July 3, 2013)
}

\begin{abstract}
Energy harvesting refers to converting ambient energy from our surroundings, which would be otherwise wasted, into useful electrical energy. A triboelectric energy harvester is a self-charged device for harnessing mechanical energy based on a coupled process of contact charging and electrostatic induction. In this research, we demonstrate simple fabrication of prototype triboelectric energy harvester using soft lithography and its electrical characterization. Triboelectric generation occurs between the two micro patterned layers of Au and PDMS. A micro pattern is simply replicated directly from the bottom layer to the top layer using soft-lithography without an extra transfer process. This generator can produce an output voltage of $2 \mathrm{~V}$ and output current of $20 \mathrm{nA}$.
\end{abstract}

Keywords : Triboelectric, Electrostatic, Energy harvesting, Nanogenerator, PDMS, Soft-lithography

\section{Introduction}

Energy harvesting devices have been studied for a decade for self-powered systems which can be applied on wireless sensor network, implanted biomedical applications, and portable electric devices $[1,2]$. Self-powered systems using various energy harvesting methods are developed in order to replace batteries or to make a hybrid charging system. Batteries have major drawbacks including its size and life expectancy, and they also pose environmental issues. As an alternative to battery, energy harvesting came up as a solution. The idea of harnessing energy from our environment is based on the sustainable, semi-permanent, maintenance-free, and eco- friendly living. Also, unlike batteries, an energy harvester does not require much space to store energy. Therefore, energy harvesting provides a better source of power for small, portable, and wireless devices.

Among various ways of harvesting energy from our surroundings [3], such as piezoelectricity, thermoelectricity, and pyroelectricity, we have chosen triboelectricity due to its potential to be miniaturized, cost effective, and efficient [4,5]. A triboelectric effect occurs as two different materials with different polarities of charge separation come into contact through friction [6,7]. The materials are separated to become electrically charged, and thus electric potential difference is achieved [8-10]. A series of recent researches have shown promising results indicating

\footnotetext{
* [E-mail] joungsoukyeo@yonsei.ac.kr
} 
that the triboelectric energy harvester is simple and cost effective. But some challenges such as the optimization of materials and the development of simpler fabrication processes still remained.

In this research, we fabricated triboelectric nanogenerators using $\mathrm{Al}$ and PDMS through a simple process using soft-lithography [11,12], and measured the output results of each harvester.

\section{Experiments}

Triboelectric energy harvester can generate electrical energy using the difference of electronegativity between two materials. Al and PDMS are used for the interficial layer between the bottom and the top electrode to produce triboelectric effect and Kapton films are used as substrates to provide flexibility. At the interfacial region, the $\mathrm{Al}$ layer and the PDMS layer have micro-roughness due to micro pillar arrays. These micro-patterns concentrate charges which are made by triboelectric effects and also increase total area of the contact region. The spacer makes a gap between two layers. A schematic image of the fabrication process of the energy harvester is shown in the Fig. 1. The fabrication process can be divided mainly into two steps for making a bottom and a top layer.

\section{Bottom layer}

A bottom layer is made of $\mathrm{Al}$ electrode on a $125 \mathrm{um}$ thick Kapton film. First, we need to make micro patterns using negative photo-resist (PR) mr-DWL-5 (Micro resist technology) and mask-less lithography system (Ez litho). Mask-less system is capable of exposing UV light with the wavelength of $405 \mathrm{~nm}$ on the $\mathrm{PR}$ at the resolution of $1 \mu \mathrm{m}$ directly from a CAD file without using a mask. The thickness of PR is $5 \mu \mathrm{m}$ and the width and the pitch of square patterns are 10 $\mu \mathrm{m}$ and $20 \mu \mathrm{m}$, respectively. These $10 \mu \mathrm{m}$ micro-patterns are designed improve electrical output in comparison with the flat surface. $10 \mu \mathrm{m}$ size patterns are more durable and are easier to replicate on PDMS compared to smaller-sized micro patterns while providing comparable electrical performances [5]. We deposited a metal layer on patterned PR with $100 \mathrm{~nm}$ thick $\mathrm{Al}$. The $\mathrm{Al}$ electrode layers were deposited by DC-Sputtering (SNTEK) at $300 \mathrm{~W}, 3$ mTorr with 30 sccm of Ar flow. The morphology of $\mathrm{Al}$ coated micro

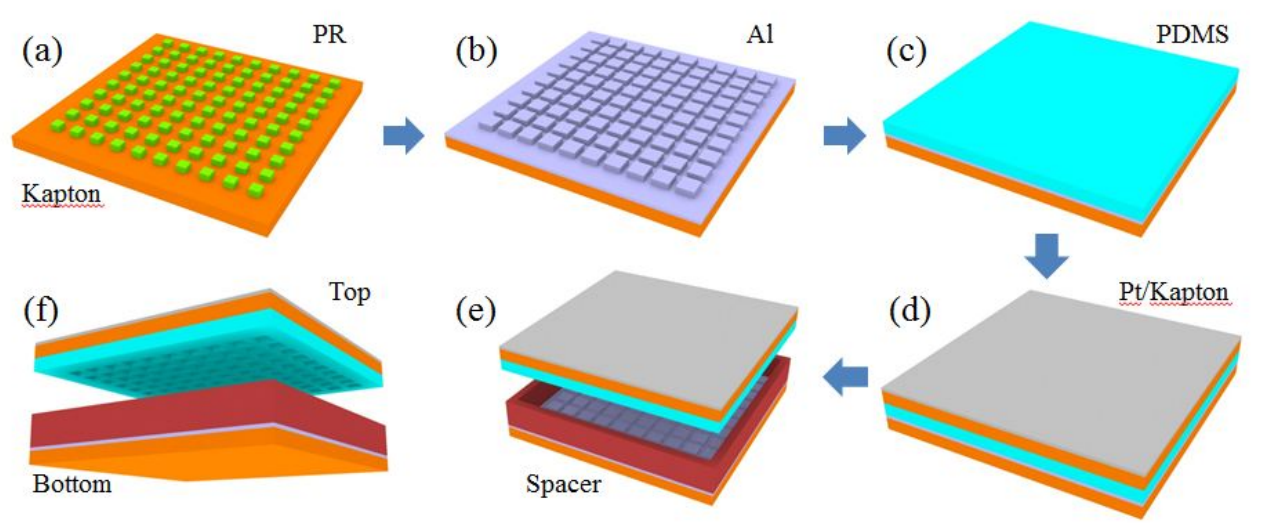

Figure 1. A schematic image of the fabrication processes of the triboelectric energy harvester, (a) PR micro patterning on a Kapton film using a maskless lithography tool, (b) Al deposition, (c) PDMS spin coating, (d) attaching the top layer on the PDMS and thermal curing, and (e) peeling off the PDMS from the bottom layer and attaching a spacer on the bottom layer. (f) An image of the negatively patterned PDMS. 


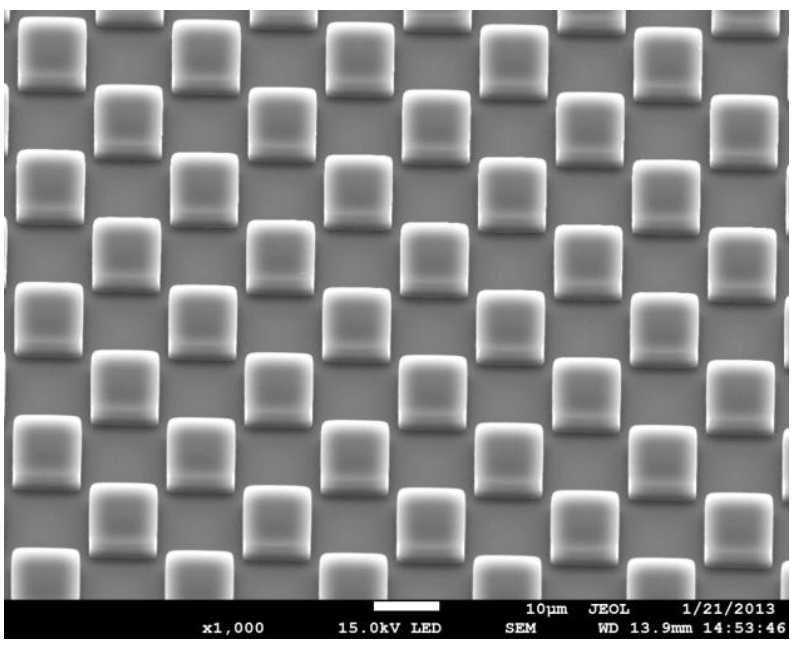

Figure 2. A SEM image of the surface of the bottom layer of Al coated PR patterns.

square array pattern is shown in Fig. 2.

\section{Top layer}

For making top layer, we deposited $80 \mathrm{~nm}$ thick Pt layer on the pre-cleaned Kapton film using DCsputter tool using the same condition described previously.

PDMS (Sylgard 184, Dow corning) was spin coated with 1,000 rpm on the top surface of the bottom layer, after de-gassing in a vacuum desiccator for $30 \mathrm{~min}$. The thickness of PDMS layer is around $100 \mathrm{~nm}$. We attached the bottom of the top layer on PDMS gently, before it is cured. Then, PDMS is thermally cured at $85^{\circ} \mathrm{C}$ for 2 hour in a Box furnace (DaeHeung). After peeling off the PDMS from the bottom layer, we can achieve the negatively replicated micro structure of square pillar arrays on the bottom-facing portion of the top layer. The morphology of the negative patterns fabricated on PDMS is shown in Fig. 3.

Spacer is made up of several layers of Kapton tapes to allow the top and bottom layers to spring back to original position after contact. The total gap between bottom and top layer is $700 \mathrm{um}$.

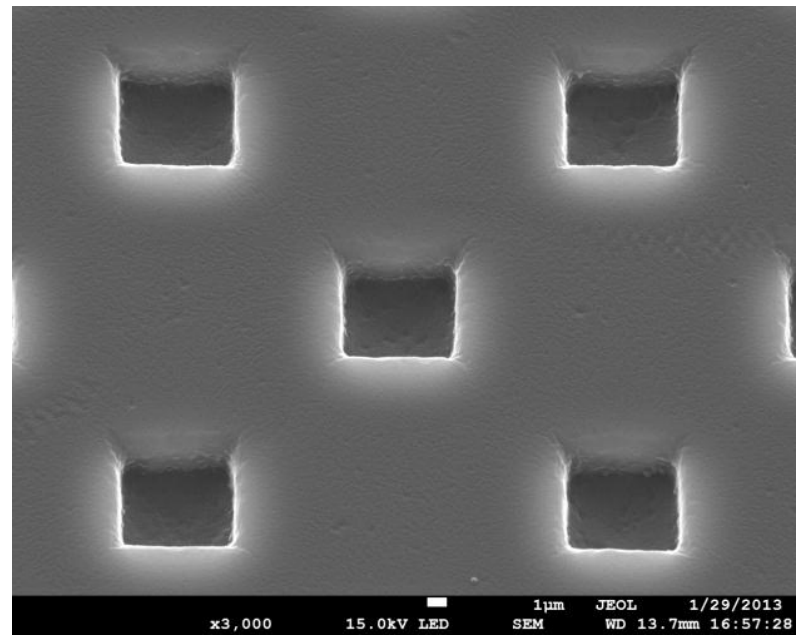

Figure 3. A SEM image of the negative pattern made of PDMS on the surface of the top layer.

\section{Characterization}

The output voltage and current are measured by a pico ammeter (Keithley 6485) and a nano voltmater (Keithley 2182), respectively. The morphologies of the square pattern on the bottom layer and its negative pattern on the top layer are characterized by a high-resolution scanning electron microscope (JEOL, JSM-7100F).

\section{Results and Discussions}

Al metal layer is coated on the top surface of the bottom layer and PDMS layer is attached on the bottom surface of the top layer. For triboelectric series of materials discussed elsewhere [13], Al is easier to lose their electrons than PDMS. When the two layers are brought into contact with each other by the external pressure such as mechanical compression, a small relative sliding between the PDMS and Al leads to the friction. Then, the micro-roughness from square pillar arrays generates the separate electrostatic charges of opposite signs on each side of the top and the bottom layers. In our case, the $\mathrm{Al}$ metal 
layer on micro pillar arrays gets positively charged while PDMS layer gets negatively charged, so that they form a triboelectric potential layer [4].

Top and bottom sides of the triboelectric energy harvester are made up of the flexible substrate, a polyimide film to provide flexibility and robustness with a total thickness under $1 \mathrm{~mm}$. The device is sufficiently flexible to be applied on human motion such as, walking, finger typing, and upper limb [1].

The size of the energy harvester is $1.02 \times 0.77 \mathrm{~cm}$. In order to measure the electrical performance of the energy harvester, we applied a pressure using finger
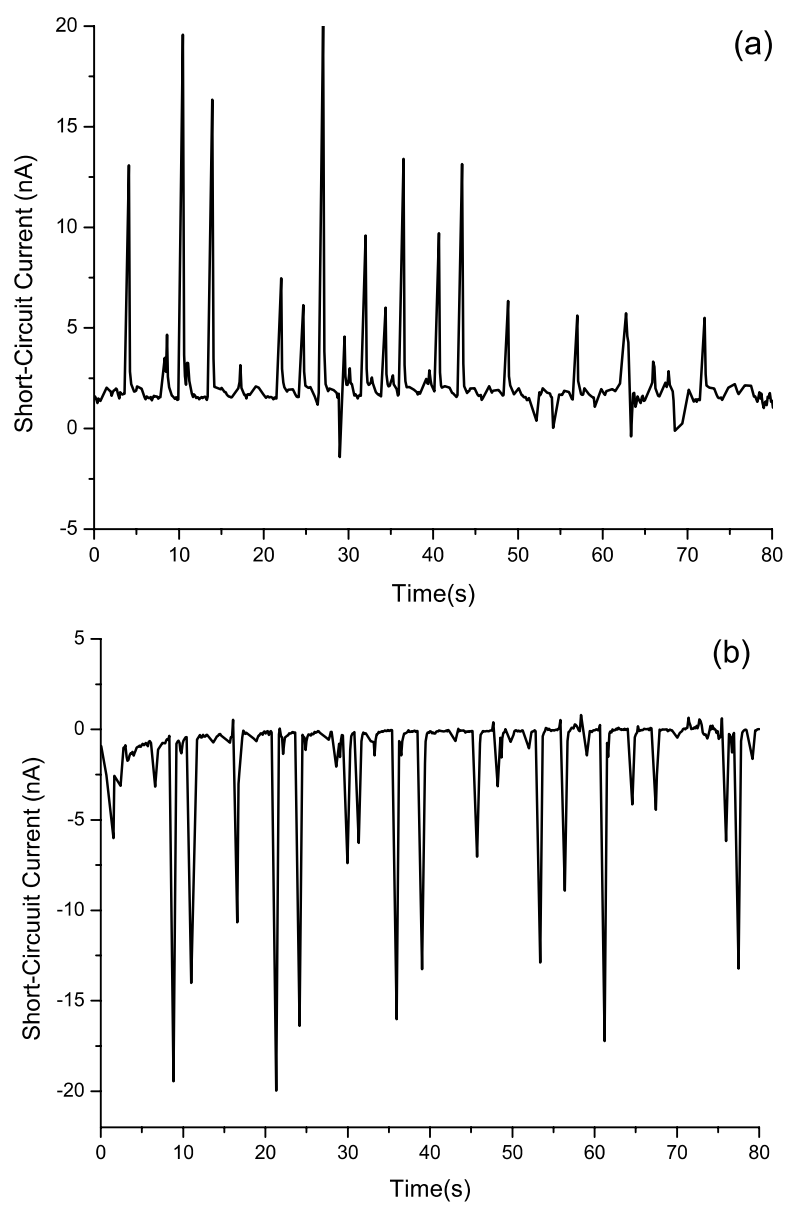

Figure 4. The output currents of triboelectric energy harvester which has the maximum currents of $\sim \pm 20 \mathrm{nA}$ and the current density of 26 $\mathrm{nA} / \mathrm{cm}^{2}$ in each case of (a) a forward shortcircuit connection and (b) a backward shortcircuit connection. typing [14]. As shown in Fig. 4, the output current is measured up to $20 \mathrm{nA}$, We performed a switching polarity test while checking the current. The magnitudes of measured output current from forward and backward connections are the same with opposite signs. From the results of the switching polarity test, we can ensure the electric potential comes from the triboelectric generation, not from either noise or applied electric potential. The output voltage is up to 2 $\mathrm{V}$ as shown in Fig. 5.

In this work, we reduce the number of process steps for the cost effective fabrication using soft lithography that can potentially be applied to roll-to-roll (R2R) tools for low cost and continuous processing. Triboelectric effect are uniformly distributed and amplified by micro patterns formed on the bottom and top layers of the energy harvester. These micro patterns are the key components of the triboelectric generator. We replicated micro patterns directly from bottom layer to top layer with a single step using soft-lithography.

\section{Conclusion}

We demonstrate a simple and cost effective fab-

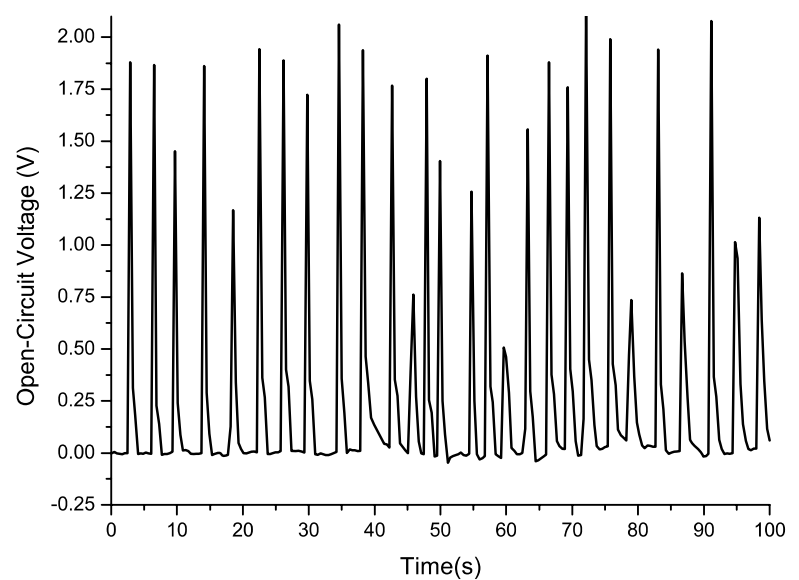

Figure 5. The output voltage of triboelectric energy harvester which has the maximum open-circuit voltage of $\sim 2 \mathrm{~V}$. 
rication of a triboelectric nanogenerator which can generate electric energy from the surrounding mechanical vibrations. We replicate micro patterns directly from bottom layer to top layer by soft-lithography using PDMS and reduce the process steps to make micro patterns on the bottom and the top layer. This method can further be applied onto the R2R process directly. Patterned square pillar arrays can easily be replicated on flexible substrates with UVcuring resin using roll-to-roll UV micro-imprinting using PDMS stamp made by soft-lithography.

The electrical performance of energy harvesters proves the basic concept and can further be improved using surface structures of nano-roughness [15] and multi stacking the energy harvesters [16]. Since the soft lithography and roll-to-roll imprinting are capable of providing required resolution in nanoscale, we believe that the fabrication concept used herein can be used to improve the electrical output further. We expect that the development of cost effective fabrication method for triboelectric energy harvester can open up a new market for self-sustainable electronics. The triboelectric energy harvester can be applied to various applications such as a self-powered active sensor [17], a mobile device, and a low power reflective display, just to name a few.

\section{Acknowledgments}

This research was supported by the MSIP (Ministry of Science, ICT and Future Planning), Korea, under the IT Consilience Creative Program (NIPA-2013H0203-13-1002) supervised by the NIPA (National IT Industry Promotion Agency).

\section{References}

[1] Z. L. Wang, Nanogenerators for Self-powered
Devices and Systems, (SMARTech digital repository, 2011), Chapter 1.

[2] Z. L. Wang, Adv. Mater. 212, 280 (2012).

[3] Z. L. Wang, G. Zhu, Y. Yang, S. Wang, and C. Pan, Materials Today 15, 532 (2012).

[4] F. R. Fan, Z. Q. Tian, and Z. L. Wang, Nano Energy 1, 328 (2012).

[5] F. R. Fan, L. Lin, G. Zhu, W. Wu, R. Zhang, and Z. L. Wang, Nano Lett. 12, 3109 (2012).

[6] G. Zhu, C. Pan, W. Guo, C. Y. Chen, Y. Zhou, R. Yu, and Z. L. Wang, Nano Lett. 12, 4960 (2012).

[7] S. Wang, L. Lin, and Z. L. Wang, Nano Lett. 12, 6339 (2012).

[8] J. A. Wiles, B. A. Grzybowski, A. Winkleman, and G. M. Whitesides, Anal. Chem. 75, 4859 (2003).

[9] L. S. McCarty, A. Winkleman, and G. M. Whitesides, J. Am. Chem. Soc. 127, 4075 (2007).

[10] L. S. McCarty and G. M. Whitesides, Angew. Chem. Int. Ed. 47, 2188 (2008).

[11] K. Y. Suh, J. Korean Vac. Soc. 16, 65 (2007).

[12] S. J. Kim, J. Korean Vac. Soc. 18, 147 (2009).

[13] A. F. Diaz and R. M. Felix-Navarro, Journal of Electrostatics 62, 277 (2004).

[14] J. Zhong, Q. Zhong, F. Fan, Y. Zhang, S. Wang, B. Hu, Z. L. Wang, and J. Zhou, Nano Energy, In press (2012).

[15] G. Zhu, Z. H. Lin, Q. Jing, P. Bai, C. Pan, Y. Yang, Y. Zhou, and Z. L. Wang, Nano Lett. 13, 847 (2013).

[16] P. Bai, G. Zhu, Z. H. Lin, Q. Jing, J. Chen, G. Zhang, J. Ma, and Z. L. Wang, ACS Nano 7, 3713 (2013).

[17] Z. H. Lin, G. Zhu, Y. S. Zhou, Y. Yang, P. Bai, J. Chen, and Z. L. Wang, Angewandte Chemie 52, 5065 (2013). 


\title{
소프트 식각법을 이용한 효율적 제작방식의 마찰전기 에너지 수확소자 개발

\author{
이준영 ${ }^{a, b} \cdot$ 성태훈 $^{a} \cdot$ 여종석 ${ }^{a, b *}$
}

${ }^{\mathrm{a}}$ 연세대학교 글로벌융합공학부, 인천 406-840

${ }^{\mathrm{b}}$ 연세대학교 미래융합기술연구원, 인천 406-840

(2013년 6월 12일 받음, 2013년 7월 3일 수정, 2013년 7월 3일 확정)

\begin{abstract}
에너지 수확은 우리주변에 존재하는 버려지는 에너지를 유용한 전기에너지로 변환하는 기술이다. 마찰전기 소자는 접촉을 통 한 정전기를 유도하는 원리로 동력학적 에너지를 전기에너지로 전환하는 소자이다. 본 연구에서는 소프트 식각 기술을 활용하 여 제작 단계를 최소화한 마찰전기 에너지 수확소자를 개발하고, 그 전기적 특성을 측정하였다. 마찰전기를 통한 발전은 마이 크로패턴을 통해 마이크로 거칠기를 가진 알루미늄 층과 PDMS 층 사이에서 발생한다. 이때 PDMS 층의 마이크로 패턴은 마 스크리스 식각을 통해 만들어진 알루미늄 층의 마이크로 패턴을 소프트 식각법으로 바로 본뜨는 방식으로 제작되었다. 본 소 자는 $2 \mathrm{~V}$ 와 $20 \mathrm{nA}$ 의 발전 성능을 나타낸다.
\end{abstract}

주제어 : 마찰전기, 정전기, 에너지 수확, 나노발전기, $\mathrm{PDMS}$, 소프트 식각

* [전자우편] joungsoukyeo@yonsei.ac.kr 